\title{
Solitary Piloleiomyoma in the Scalp
}

\author{
Dong Hwi Kim¹, \\ Ji Sung Lee ${ }^{1}$, \\ Jean A Kim², \\ Jung Ho Lee ${ }^{1}$ \\ Departments of ${ }^{1}$ Plastic and Reconstructive \\ Surgery and ${ }^{2}$ Clinical Pathology, Bucheon \\ St. Marys Hospital, College of Medicine, The \\ Catholic University of Korea, Bucheon, Korea
}

No potential conflict of interest relevant to this article was reported.

\begin{abstract}
Cutaneous leiomyomas can be classified into three types according to the site of origin: piloleiomyoma, angioleiomyoma, and dartoic (genital) leiomyoma. It might be expected that leiomyomas are commonly found on the scalp because there are many arrector pili muscles and vessels. However, leiomyomas are actually rarely reported in the scalp. Recently, we observed a case of cutaneous leiomyoma in the scalp and present our experience along with a literature review.
\end{abstract}

Keywords: Leiomyoma / Scalp / Skin neoplasms / Smooth muscle / Hair follicle

\section{INTRODUCTION}

Leiomyoma is a benign soft tissue tumor originated from smooth muscle tissue. It can appear in any location where smooth muscle exists. The most common location is uterus (about 95\% of all leiomyoma), and the skin is the second most common location for leiomyoma, comprising about $3 \%-5 \%$ of all leiomyoma [1]. Cutaneous leiomyoma arises from smooth muscle in the skin, such as arrector pili muscle (pilar leiomyoma), media in the blood vessel (angioleiomyoma) and smooth muscle in the scrotum or labium (genital leiomyoma). Although there are numerous many hairs and blood vessels in the scalp, cutaneous leiomyoma in the scalp has been reported very rarely [2].

Recently, we observed a case of cutaneous leiomyoma on scalp and successfully treated with complete resection. We report our experience of this rare case with literature review.

Correspondence: Jung Ho Lee

Department of Plastic and Reconstructive Surgery, Bucheon St. Mary's Hospital, College of Medicine, The Catholic University of Korea, 327 Sosa-ro, Wonmi-gu, Bucheon 14647, Korea E-mail: tfm0822@catholic.ac.kr

Received December 22, 2016 / Revised March 4, 2017 / Accepted March 4, 2017
CASE REPORT

A 31-year-old male patient visited our out-patient department with a chief complaint of slowly growing mass in the frontal scalp (Fig. 1). He said it was noticed about 18 months before the visit. The mass was painless and there was no additional palpable mass on the rest of his body. Trauma and family history was also negative. On physical examination, there was about $1 \mathrm{~cm}$ sized firm and pinkish mass in the frontal scalp.

At first, we considered it as fibroma. A punch biopsy was performed and it was diagnosed with pilar leiomyoma. Although there was no associated symptom, complete excision was done because the patient wanted it to be removed.

Histolopathologically, there were nonencapsulated spindle shaped cell bundles with whirly appearance in hematoxylin and eosin stained slide. The mass was adjacent to arrector pili muscle of hair and the margin of the mass was irregularly mixed with dermal collagen (Fig. 2A). No cellular atypia or necrotic lesion was seen and mitotic activity was not apparent (Fig. 2B). Immunohistochemically, the spindled cells were highly positive for alphasmooth muscle actin (Fig. 3), but negative for S-100 protein, which is consistent with the diagnosis of pilar leiomyoma. 


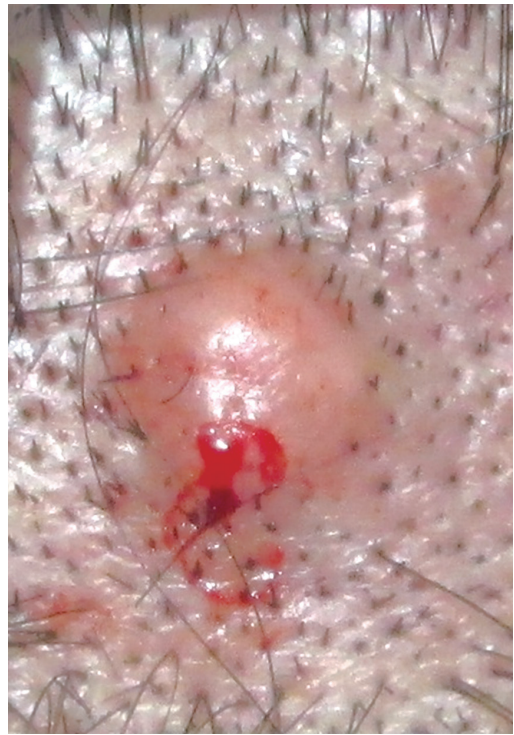

Fig. 1. Preoperative photography shows about $1 \times 1 \mathrm{~cm}$ sized nodular and pinkish mass in the scalp.
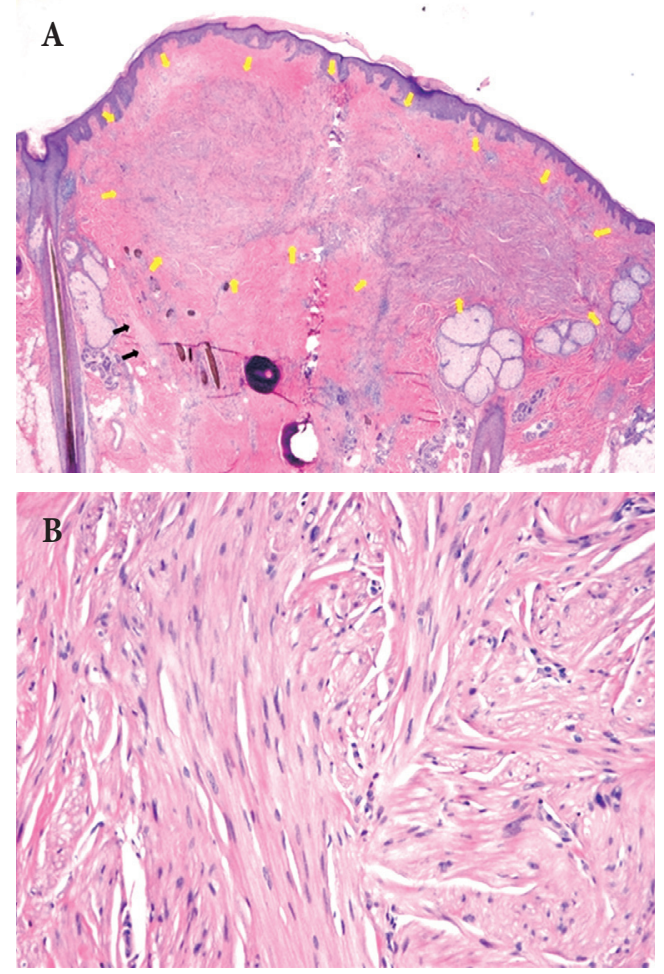

Fig. 2. (A) The histopathologic examination shows spindle-shaped cells arranged in whirls and fascicles. The mass is adjacent to arrector pili muscle (black arrows). The tumor margin is irregularly mixed with dermal collagen (yellow arrows) (H\&E, $\times 20$ ). (B) The high-power histologic examination shows the indistinctive cytoplasmic membranes and blunt-ended nuclei. There are no cellular atypia, abnormal mitotic activity or necrosis $(\mathrm{H} \& \mathrm{E}, \times 400)$.

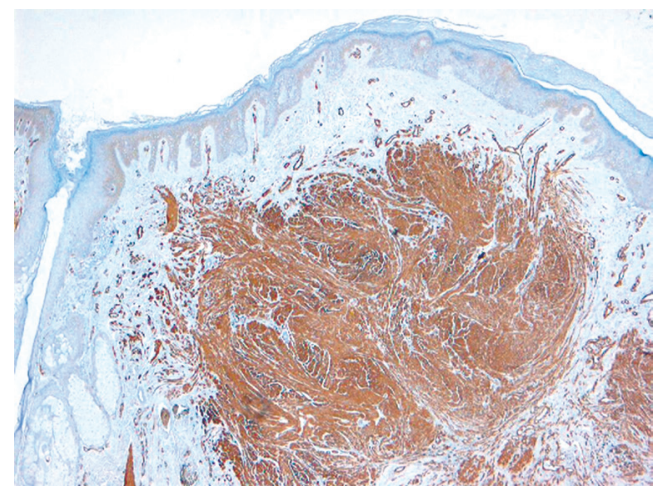

Fig. 3. Immunohistochemistrical study for alpha-smooth muscle actin confirms the diagnosis of cutaneous leiomyoma (H\&E, $\times 40$ ).

\section{DISCUSSION}

According to the origin, cutaneous leiomyoma can be classified into three types. Piloleiomyoma is the most common type of cutaneous leiomyoma. It arises from the pilomotor muscle and can be found solitary or multiple. The usual onset time of age is adolescence or early adult life. The pilar leiomyoma affect the sexes equally, in spite of overall leiomyoma show dominant in female (female:male=3.75:1). Typical piloleiomyoma shows red-brown, firm, rounded or oval smooth nodules. The most commonly affected area is the extensor surface of the extremities. Pain is often accompanied although the cause of pain is not clear whether it is produced by contraction of the muscle tissue or compression of nearby nerves. The pain can be aggravated by touch, exposure to cold or emotional disturbance [2]. Histologically, it is usually located in the dermal layer and irregularly mixed with surround dermal collagen. It is less well-defined than vascular leiomyoma and reasonably, adjacent arrector pili muscle. The cells composing the mass are similar to normal smooth muscle cells $[1,3]$.

Genital leiomyoma can be observed on the areola of the nipple, scrotum, labium, penis, and vulva. It is usually smaller than piloleiomyoma and does not accompany pain. Histologically, it is differ from piloleiomyoma, for instance, it is more circumscribed and more cellular [1].

Vascular leiomyoma accounts for one-fourth to one-half of all superficial leiomyomas. It was not distinguished from cutaneous leiomyoma in early literatures but it usually found in the subcuti- 
cal layer and is composed of many thick-walled vessels, unlike cutaneous leiomyoma, which has few thin-walled vessels in it. Vascular leiomyoma is well-circumscribed than cutaneous leiomyoma and commonly occurred between age from 40 to 60 . Solitary lesions are more common than multiple and most commonly affected site is lower extremities. Half of patients with vascular leiomyoma complain of pain, aggravated with pressure or temperature change. Histologically, vascular leiomyoma can be classified into three groups, capillary or solid (67\%), venous (23\%) and cavernous (11\%) type $[1,4,5]$.

One can commonsensically think that leiomyoma can be commonly found on the scalp, because there are many arrector pili muscles and vessels. However, regardless of subtypes, to our knowledge, few cases of scalp leiomyoma have been reported in previously published articles. Arishima el al. [6] reported a 6-yearold boy with a vascular leiomyoma and Lotfi el al. [7] presented a 5-month-old boy with cutaneous leiomyoma. There are many possible differential diagnosis for the mass on scalp. When the mass was palpated on scalp, trichilemmal cyst, epidermal cyst, intradermal/epidermal nevus, sebaceous cyst, seborrheic keratosis and hemangioma can be suspected. Clinical findings of lipoma, fibroma, neurofibroma and dermatofibroma are also similar to those of leiomyomas and it is possible that a malignant neoplasm such as basal cell carcinoma and squamous cell carcinoma whether it is primary or metastatic, can be found on scalp, too $[5,8,9]$.

The treatment options for leiomyoma vary depending on its location, the number of lesions and the associated symptoms. It can be successfully treated with surgical resection in a solitary lesion and if it is well-resected with appropriate margin, recurrence is very rare [5]. However, the surgical excision is sometimes not recommended in patients with multiple lesions when it is extensive and recurrence is very common even if they are all resected [10]. If the lesions are associated with pain, various medical therapies such as calcium channel blocker, phenoxybenzamine, doxazosin, and gabapentin can be applied. And also, injection of Botulinum toxin might be offered to be an adjuvant therapy for pain relief $[11,12]$.
In summary, clinical diagnosis of cutaneous leiomyoma is very difficult and the diagnosis is mainly based on histological features. Although rare, one should consider cutaneous leiomyoma to be included in the differential diagnosis for papulonodular lesion in the scalp, and preoperative biopsy should be performed. There are many treatment options for cutaneous leiomyoma, but if it is solitary complete excision is the sufficient and definite treatment.

\section{REFERENCES}

1. Goldblum JR, Folpe AL, Weiss SW. Benign tumors of smooth muscle. In: Goldblum JR, Weiss SW, Enzinger FM, editors. Enzinger and Weiss's soft tissue tumors. 6th ed. Philadelphia: Elsevier Saunders; 2014. p. 524-48.

2. Fatima Q, Singh O, Kothari DC, Godara SK. Cutaneous leiomyoma of scalp: a rare case report with review of literature. Int J Res Med Sci 2015;3:993-7.

3. Shaaban D, El-Adawi E, Al-Mutairi A. Cutaneous leiomyoma: case reports. Gulf J Dermatol Venereol 2010;17:61-3.

4. Hachisuga T, Hashimoto H, Enjoji M. Angioleiomyoma: a clinicopathologic reappraisal of 562 cases. Cancer 1984;54:126-30.

5. Veeresh M, Sudhakara M, Girish G, Naik C. Leiomyoma: a rare tumor in the head and neck and oral cavity: Report of 3 cases with review. J Oral Maxillofac Pathol 2013;17:281-7.

6. Arishima H, Takeuchi H, Kitai R, Yamauchi T, Kikuta K. Vascular leiomyoma of the scalp with a small deformity on the skull mimicking a dermoid cyst. Pediatr Dermatol 2013;30:e27-9.

7. Lotfi S, Ghalamkarpour F, Rahimi H, Kani ZA, Yousefi M, Qaisari M. An ulcerated tumor in an infant. Dermatol Online J 2010;16:9.

8. Turk CC, Bacanli A, Kara NN. Incidence and clinical significance of lesions presenting as a scalp mass in adult patients. Acta Neurochir (Wien) 2015;157:217-23.

9. Brooks JK, Nikitakis NG, Goodman NJ, Levy BA. Clinicopathologic characterization of oral angioleiomyomas. Oral Surg Oral Med Oral Pathol Oral Radiol Endod 2002;94:221-7.

10. Holst VA, Junkins-Hopkins JM, Elenitsas R. Cutaneous smooth muscle neoplasms: clinical features, histologic findings, and treatment options. J Am Acad Dermatol 2002;46:477-90.

11. Dilek N, Yuksel D, Sehitoglu I, Saral Y. Cutaneous leiomyoma in a child: a case report. Oncol Lett 2013;5:1163-4.

12. Onder M, Adisen E. A new indication of botulinum toxin: leiomyoma-related pain. J Am Acad Dermatol 2009;60:325-8. 